\title{
Iglesias-Fortaleza en la costa mediterránea española en el Siglo XVI
} Antonio Palenzuela Navarro

Universidad de Sevilla, Almería, España, apalenzuelanavarro@icloud.com

\begin{abstract}
This heritage study focuses on in-depth analysis of the churches within the fortress defense systems designed in modern period in the geographical context of the Spanish Mediterranean coast, with special detail on the Mediterranean Spanish coast. It is defensive systems that have established restricting borders of land, commercial and religious antagonistic throughout history and virulently in the Modern Age interests, and even then consolidated as structures of features and easily verifiable common elements, in highlighting a common singularity them all the establishment of a new dual typology, between the religious and military, who are the Church-Fortress.
\end{abstract}

Keywords: Church, fortress, defense system, typology.

\section{Introducción}

La historia de la piratería en el Mediterráneo abarca varios siglos, incluso desde el final de la Edad Media, donde existía un tráfico marítimo establecido con rutas que van de norte a sur, de reinos cristianos como el de Aragón a territorios que componen Al-andalus, y el norte de África. Un tráfico que propiciará actividad económica e intercambios a ambas orillas del Mediterráneo, independientemente de la religión que se profesase.

Será a partir de 1500 cuando tienen lugar las incursiones berberiscas y turcas. Normalmente se trataba de piratas bereberes del norte de áfrica que atacaban las poblaciones del Mediterráneo, especialmente la costa sur-levante mediterránea española, las Islas Baleares, Cerdeña, Córcega, Sicilia y la península itálica.

También se le llamarán turcos por ondear la bandera de la media luna, como símbolo de su posición contraria a los reinos cristianos. Es por lo que ser popularizará la expresión "hay moros en la costa" la cual se hizo frecuente en todo el litoral español, con independencia de que los atacantes fueran de otra procedencia, religión o raza. (Sancho Pons, 2004: 36).

Será el momento de los desembarcos berberiscos de Cullera (1503) y Denia (1518), o en Teulada (Ivars, 1988: 51), actividades que seguirán ocurriendo en estos años en demás poblaciones litorales acompañado de la presencia de mayoría musulmana en los valles del interior cercanos a línea de costa, como es el caso de la Alpujarras en Reino de Granada, o los valles del Ricote en Murcia y valles interiores del Reino de Valencia.

Ante esta persistente situación de continuas razias y ataques en el litoral mediterráneo de la corona hispánica por parte de las embarcaciones berberiscas y demás corsarios, se dieron respuestas constructivas similares desde los diferentes reinos a través de una arquitectura defensiva marítima, entre las cuales destaca la iglesia-fortaleza, una nueva tipología dual, entre lo religioso y militar, inserto en un sistema de defensa de fronteras delimitadoras de intereses territoriales, comerciales y religiosos antagónicos. 


\section{La Iglesia-Fortaleza en el sistema defensivo costero mediterráneo}

Se trata de un patrimonio que nace entre los convulsos enfrentamientos militares entre sur y norte del Mar Mediterráneo desde Edad Media hasta el S.XVII, que surgen como arquitecturas defensivas que servirán para proteger a la población, controlar y prevenir de futuros ataques.

Dentro de las construcciones defensivas que se construyen en ambas orillas del Mediterráneo hay una tipología que va a destacar y se va a mantener con unas características morfológicas y funcionales similares. La Iglesia-Fortaleza es esa tipología que va a unirse dentro de una cadena defensiva, como un eslabón más de ella. Esta construcción va estar íntimamente ligada a la costa mediterránea de Europa Occidental, y su aparición va a coincidir con el inicio, apogeo y expansión del Imperio Otomano y la nueva relación política de los estados europeos con el corso, durante los siglos XIV, XV y con especial fuerza en el siglo XVI.

Lo que en principio será la construcción de iglesias que para defender a su población incorporen elementos más propios de la arquitectura militar que de la religiosa, como torres o almenados, va a desembocar en la construcción de edificios con un fuerte sentido defensivo, donde los parámetros de una arquitectura puramente religiosa quedan relegados a un segundo plano.

\subsection{Ejemplos de Iglesias-Fortaleza en la costa mediterránea española}

Queremos estructurar esta descripción de la tipología en base a la localización geográfica en la cual se inserta. En base al estudio realizado, detectamos tres principales zonas de influencia en las que se desarrollará esta arquitectura defensiva con características estilísticas y formales similares.

Por tanto, estructuramos esta clasificación en tres zonas:

-El Reino de Valencia, cuya actividad comercial se desempeñará principalmente en el Grao de
Valencia y la costa alicantina. Será en las calas de ésta última donde el corso se haga fuerte, convirtiéndose en puntos de desembarco de las naves corsarias en el S.XV procedentes del Reino Nazarí de Granada (Hinojosa Montalvo, 1997: 427) y de piratas berberiscos procedentes de Argel a partir del S.XVI. Esta franja de tierra frente al mar será colonizada por viejos cristianos que comunicarán con el interior a través de los nuevos sistemas defensivos, entre ellos torres y bastiones, y nuevas parroquias, muchas de ellas iglesias-fortaleza.

Este fenómeno lo vemos reflejado especialmente en las comarcas alicantinas de la Marina Alta y la Marina Baja, donde la sucesión de valles y accidentes geográficos costeros propiciaría un escenario ideal para las incursiones piráticas, donde se han detectado más de diez ejemplos de iglesias-fortaleza, entre las que destacamos San Bartolomé de Jávea, Santa Catalina de Teulada, San Miguel Arcángel de Murla o Nuestra Señora de la Asunción en Villajoyosa.

-En Islas Baleares, especialmente en las Pitiusas (Ibiza y Formentera), padecieron los continuos ataques de turcos y berberiscos a lo largo del S.XVI. Con la llegada al trono de Carlos I en 1516 las defensas del norte de África se fueron debilitando al no dotarlas de recursos económicos (Rodríguez-Salgado, 1992, 376). Ello provocará el acoso turco-berberisco de Formentera e Ibiza, ahora en primera línea. Los desembarcos se sucederán en la zona de Santa Eularia y Formentera en los años 1535,1541 y 1543. Es allí donde se fundarán San Antonio, San Miguel, Santa Eularia y San Jorge (Serra Rodríguez, 2000: 13).

-El Reino de Granada, donde la cristianización del antiguo reino musulmán, será llevada a cabo entre otras acciones, por medio de la Bula de Erección de las Iglesias del Arzobispado de Granada en 1501, y en 1505 a través de las diócesis de Almería, Málaga y Guadix (Martín García, 2013: 611). En este marco geográfico destaca la costa almeriense con tres ejemplos, como son la Iglesia de la Encarnación de Vera, la Catedral-Fortaleza de Almería y Santa María de Mojácar. 


\subsection{Características de las Iglesias-Fortaleza}

De los casos estudiados, se puede constatar lo siguiente:

-Se sitúan en un arco de proximidad con la costa no mayor de 5 a $10 \mathrm{Km}$. En esta franja de territorio se van a encontrar los otros elementos fortificados que van a ayudar la construcción de una cadena de resistencia defensiva.

-Se insertan como un elemento más dentro de una línea defensiva de más construcciones como murallas, torres y presidios. La defensa del territorio parte de una estrategia global y territorial, por lo que las iglesias-fortaleza formaban parte del engranaje sistémico de la cadena defensiva costera.

- Son construidas en piedra con técnicas de aparejo de sillares o mampostería, similares a otras construcciones meramente defensivas como las murallas o cubos de defensa. Esta característica es la más acusada y común entre todos los ejemplos estudiados y se debe en gran parte a ser el material más prescrito por todos los tratados del momento histórico en cuestión, ya que toda la tradición de la poliorcética y de la castrametación así lo había ido perpetuando.

- Espacialmente están compuestas por una o tres naves con alturas comprendidas en un intervalo de 10 a 15 metros, todas ellas a la misma cota, al modo halleskirche, manifestándose exteriormente sus contrafuertes. Es una maniobra espacial que permitía una cubierta plana en su nivel superior necesaria para una mejor distribución de los recursos defensivos.

- Presentan cubiertas planas, a modo de terrazas, con un peto que puede estar almenado o no, que rodea perimetralmente toda la planta del edificio. Esta es una parte esencial de la estructura de las iglesiasfortaleza, ya que gracias a esta formalización arquitectónica, permitía el ataque y defensa de su entorno más próximo y de la propia iglesia. Además estas cubiertas planas facilitaban el movimiento de los efectivos que realizaban la defensa pudiendo trasladarse con rapidez a los distintos flancos de ataque, como así transportar cañones $\mathrm{u}$ otras armas y recursos defensivos que precisaban de una superficie continua y horizontal.

- La cubrición de las naves normalmente se desarrolla con técnicas tardo góticas, como la bóveda de crucería, aunque también se emplean en otros casos la bóveda de medio cañón. Como regla general, estas son las técnicas más usuales debido en gran parte a su natural fortaleza estructural, y a la propagación de estas técnicas que se desarrollan en un momento histórico, en torno a los siglos XV y XVI, donde solían ser las técnicas empleadas de manera mayoritaria por toda una sociedad.

- Destaca la austeridad de sus alzados exteriores, donde los muros aparecen como lienzos desnudos, despojados de decoración, la cual sólo aparece en las portadas. Es una característica fácilmente reconocible en todas ellas, que tienen su razón de ser en su mero carácter funcional defensivo, donde las fachadas se convierten en grandes paños amurallados que tienen que resistir en envite de los proyectiles y otras armas arrojadizas. De modo que la decoración cuando hace acto de aparición quedará recluida a lugares puntuales e incluso a zonas residuales desde el punto de vista defensivo. En la mayoría de los casos este ornamento propio de la simbología cristiana y con claro mensaje evangelizador se reservará a algunas de sus portadas, aunque siempre de una manera discreta y a veces de una factura un tanto pueril y arcaica, a excepción de algunos ejemplos como la Catedral-Fortaleza de Almería.

- Incorporan torres de defensa, que funcionan como los bastiones de los castillos medievales. Actualmente, muchos de los ejemplos conservados se han convertido en campanarios tras sucesivas remodelaciones en los siglos posteriores, incorporando nuevos cuerpos a las torres y desvirtuando su diseño original. Eran los oteadores funcionales del edificio defensivo, desde estas torres se comunicaban con el resto del sistema defensivo y permitían advertir a la población de los inminentes ataques o desembarcos que iba sufrir la población. 


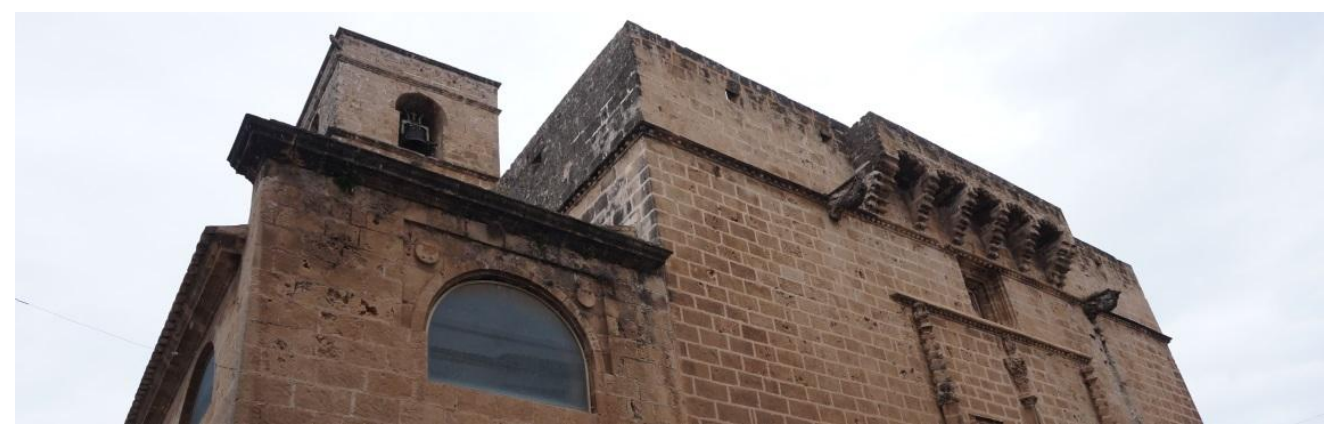

Fig. 2- Iglesia-Fortaleza de San Bartolomé en Jávea, Alicante (Elaboración propia)

\section{Conclusiones}

Se puede constatar que es una tipología que se va a desarrollar de una manera sistemática distinguiéndose dos fases de implantación. La primera fase se desarrollará en torno a los siglos XIV y XV dentro del llamado arco mediterráneo europeo, encontrando ejemplos de estas iglesias en la costa de la Provenza y el Rosellón francés, Liguria italiana e Islas Baleares. Esto tiene gran sentido, si se entiende que la frontera del mundo musulmán estaba situada en ese momento más al norte del Magreb africano, existiendo territorio islámico en la propia península ibérica (Reino Nazarí), además de contar con una gran población musulmana que ayudaba a financiar las razias tanto dentro de la península ibérica, como en la propia Sicilia, que había llegado a ser un emirato hasta el año 1072. Conforme la reconquista cristiana avanza y desaparecen los últimos reinos musulmanes en Europa, se desarrolla una segunda fase en los siglos XVI y XVII, donde tendrá una expansión más intensa la iglesia-fortaleza, implantándose en los enclaves más al sur de Europa, y por tanto en primera línea de guerra con la frontera musulmana, en el Reino de Valencia y el Reino de Granada. Unas iglesias que van a formar parte de la red defensiva costera de la época, incorporadas dentro de un marco geográfico común y en un momento concreto de la historia, el siglo XVI, de ahí la necesidad de abordar esta investigación en mayor detalle en posteriores investigaciones para entender el proceso de desarrollo y proliferación de la mencionada tipología en la costa mediterránea.

\section{Referencias}

Hinojosa Montalvo, J.R. (1997) El Reino de Valencia: frontera marítima entre Aragón y Granada. Actas del Congreso la Frontera Oriental Nazarí como Sujeto Histórico (S.XIII-XVI): Lorca-Vera, 22 a 24 de noviembre de 1994. Universidad de Alicante, 1997, pp. 409-434.

Ivars Pérez, J. (1988) La vila de Teulada. Procés de fortificació i estructura urbana. Aguaits: Revista d'investigació i assaig. Ed. Institut d'Estudis Comarcals de la Marina Alta, nº1, 1988, pp. 49-64.

Martín García, M. (2013) Iglesias fortificadas del Reino de Granada. Huerta, Santiago y Fabián López Ulloa Ed. Actas del Octavo Congreso Nacional de Historia de la Construcción. Madrid, 9-12 de octubre de 2013. Madrid: Instituto Juan de Herrera, 2013, pp. 611-620.

Mora Piris, P. (2010) Tratados y Tratadistas de fortificación. Siglos XVI al XVIII. En Posada Simeón, J.C. Cartografía histórica en la Biblioteca de la Universidad de Sevilla, Sevilla, 2010, pp. 120-147.

Sancho Pons, E. (2004) Moros en la costa. Sociedad Geográfica Española, nº 18, 2004, pp. 30-47.

Serra Rodríguez, J.J. (2000) Fortificaciones rurales en la Isla de Ibiza: las torres de refugio prediales. Barcelona. Ed. Escuela Universitaria de Arquitectura Técnica de Valencia. Mediterrania-eivissa. 2000 . 